\title{
What do patients think about HIV mass screening in France? A qualitative study
}

\author{
Marie Paule Fernandez-Gerlinger ${ }^{1}$, Erik Bernard ${ }^{2}$ and Olivier Saint-Lary ${ }^{2 *}$
}

\begin{abstract}
Background: Since 2009, HIV mass screening of the 15-70-year-old general population in low-risk situations has been recommended in France. This, not yet implemented, untargeted screening would be cost-effective with a positive impact on public health. No previous studies had interrogated primary care patients about it. This study aimed at exploring perceptions of patients attending general practitioner's on HIV mass screening and at identifying barriers to its implementation.

Methods: We conducted a qualitative study through semi-structured individual interviews. Participants were recruited according to age, gender and location of their physician's practice. Data analysis was based on triangulation by two researchers.

Results: Twenty-four interviews were necessary to obtain data saturation. HIV transmission was mostly associated with sexual intercourse; main barriers stemming from the screening were related to sexuality, often seen as questioning spouse's faithfulness. It could interfere with religiosity, implying an upsetting perception of sexuality among the elderly. Patients' beliefs and perceptions regarding HIV/AIDS, the fear to be screened and difficulties to talk about sexuality were other barriers.

Conclusion: To our knowledge, no studies had previously interrogated primary care patients about barriers to HIV mass screening in France. Although relevance of this untargeted screening is debated in France, our results could be helpful to a better understanding of patients' attitudes toward this and to an outstanding contribution to reduce the number of new cases of HIV contamination.
\end{abstract}

\section{Background}

About 33 million people are infected with the human immunodeficiency virus (HIV) worldwide [1]. In France, approximately 150,000 people are HIV-positive, among them 50,000 being unaware of it [2-4]. Between 6,000 and 8,000 new HIV-positive diagnoses are made each year, a third of these at an AIDS stage. In 2004, according to the French Institute for Public Health Surveillance (Institut de veille sanitaire, InVS), $47 \%$ of adults were not aware of being HIV-positive at the time of the diagnosis of AIDS, $46 \%$ of them were heterosexuals born in France [5]. In 2009, 62\% of cases of infection resulted from heterosexual contact, and over $50 \%$ of urban cases occurred in Île-de-France [6].

\footnotetext{
*Correspondence: olivier.saint-lary@uvsq.fr

${ }^{2}$ Department of General Medicine, Faculty of Health Sciences Simone Veil, University of Versailles Saint-Quentin-en-Yvelines, Montigny le Bretonneux, France

Full list of author information is available at the end of the article
}

Since 2009, mass screening of the low-risk 15-70year-old general population has been recommended. This screening would be beneficial in terms of public health and cost-effective [7] although a recent French study questioned its utility [8]. Early diagnosis of HIV infection would have an individual and collective positive impact [9-14].

This untargeted screening in general population is not currently implemented in common practice and the 2009 recommendation has not made any change as the number of newly diagnosed HIV-positive cases has been stable since 2008 [15].

The use of qualitative methods is becoming more common in medical research in general and about HIV in particular [16,17] but few studies focused on the "patient" viewpoint [18]. The question of mass screening in general population has been mainly studied from a medico-economic perspective and in terms of public health impact $[14,19-25]$. Some qualitative studies have

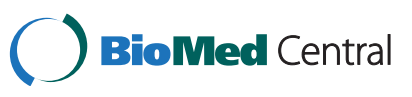


been conducted in the United States on the brakes and acceptance of HIV testing in primary care clinic in San Francisco [26] or querying only seropositive for HIV [27]. In the United Kingdom one study queried the feasibility of a rapid test in primary care [28]. But to our knowledge, no study has directly interviewed primary care patients in France about the opportunity of HIV mass screening.

Our study aimed at exploring perceptions of patients attending general practitioner's on HIV mass screening and at identifying barriers to its implementation.

\section{Method}

\section{Study type}

A qualitative study through semi-structured individual interviews was performed [29,30]. Individual interviews were preferred to focus groups because the HIV theme is related to the private sphere and to sexuality and could compromise the quality of group exchanges [31]. We adhered to the RATS guidelines.

\section{Recruitment of participants}

General practitioners exercising in Yvelines (one of the eight departments of the Île-de-France region, France) and internship supervisor at the Faculty of Health Sciences of Paris-Ile-de-France-Ouest invited their patients to take part in the study. The patients were recruited according to their age and gender, as well as the location of their physician's practice, in order to obtain a great diversity. The participants should be aged 18 to 70 but we deliberately did not include minor patients $(<18$ year old) due to ethical issues and interview feasibility (a written agreement of both parents would have been required). A HIV-positive status already known by their attending physicians was an exclusion criterion.

The number of interviews was not set in advance. The objective was to achieve data saturation, defined in our study as the lack of any new theme raised during three consecutive interviews. Oral consent was sought systematically before each interview both by their attending GP and by the interviewer. The participants were advised that the interview could be interrupted at any time.

\section{Management of the interviews}

The interviews were conducted by an intern of general medicine and took place at the practice of three general practitioners who were internship supervisors at the faculty of health sciences of Paris-Île-de-France-Ouest. Interviews took place in a quiet separate room, in order to respect patients' privacy. An interview guide that was intentionally undetailed in order to facilitate expression (Appendix 1) was used to guide the interviews. Questions were deliberately open to limit potential bias linked to the researchers' opinions on the subject [32]. Completion questions were provided in order to get more detailed answers but they were intentionally kept at a minimum. The participants were not incentivized.

\section{Data analysis}

Several steps were followed to realize an inductive analysis of thematic content, with category construction based on analysis of the participants' opinions. The inductive approach is a systematic procedure to analyze qualitative data in which the identified themes are a cluster of meaning like connected categories. Its primary purpose is to allow research findings to rise from the frequent, dominant or significant themes inherent in raw data. All the interviews were led by a resident in general practice, lasting from 3 to 15 minutes. Each individual interview was audio-recorded using two digital voice recorders, then transcribed into a computer file (Word). The recordings were destroyed after analysis out of respect for medical confidentiality and the private nature of the recorded data. The verbatim transcriptions were read several times, choosing units of meaning, identifying general themes, categorizing and classifying. The investigators' triangulation involved two different researchers in the analysis process. The same method was used by each of them to analyze the data. Each evaluator's findings were compared in order to optimize the data conformity.

\section{Ethical statement}

The study has been reviewed by an ethics committee, the "Comité de Protection des Personnes Île-de-France $X I^{\prime \prime}$ and the committee conclusions were that an ethical approval was not required under French law (law of the August 9, 2004).

\section{Results}

In total, 24 interviews were needed to achieve data saturation. The participants (41-years-old in average) included 11 men and 13 women (Table 1 ).

\section{Barriers to the HIV mass screening related to sexuality}

Most of interviewed patients associated HIV transmission with sexual relations, so they considered that the screening inevitably questioned their spouse's fidelity: "we cannot always have suspicions and get screened every 6 months" (female patient no. 2). Marriage was seen by some as a guarantee of fidelity and therefore made the screening unnecessary: "All married couples, if they're faithful, I don't think they need to be screened" (male patient no. 9). Similarly, religion (Catholicism in our study) was supposed to protect patients from high-risk relations: "young, very devout Catholics [...] would only ever have sexual relations with their wife or husband [...], 
Table 1 Characteristics of participants $(n=24)$

\begin{tabular}{|c|c|c|c|}
\hline Patient & Age & Gender & Location of physician's practice \\
\hline Patient 1 & 44 & Female & Marly le Roi \\
\hline Patient 2 & 37 & Female & Marly le Roi \\
\hline Patient 3 & 68 & Male & Marly le Roi \\
\hline Patient 4 & 62 & Male & Marly le Roi \\
\hline Patient 5 & 70 & Male & Marly le Roi \\
\hline Patient 6 & 47 & Female & Marly le Roi \\
\hline Patient 7 & 39 & Male & Marly le Roi \\
\hline Patient 8 & 25 & Male & Versailles \\
\hline Patient 9 & 34 & Male & Versailles \\
\hline Patient 10 & 20 & Male & Versailles \\
\hline Patient 11 & 49 & Female & Versailles \\
\hline Patient 12 & 33 & Male & Versailles \\
\hline Patient 13 & 53 & Female & Versailles \\
\hline Patient 14 & 19 & Female & Versailles \\
\hline Patient 15 & 51 & Male & Rambouillet \\
\hline Patient 16 & 20 & Female & Rambouillet \\
\hline Patient 17 & 53 & Female & Rambouillet \\
\hline Patient 18 & 54 & Female & Rambouillet \\
\hline Patient 19 & 31 & Female & Rambouillet \\
\hline Patient 20 & 69 & Female & Rambouillet \\
\hline Patient 21 & 40 & Male & Rambouillet \\
\hline Patient 22 & 40 & Female & Rambouillet \\
\hline Patient 23 & 21 & Male & Versailles \\
\hline Patient 24 & 18 & Female & Versailles \\
\hline
\end{tabular}

they don't even talk about HIV at home" (female patient no. 24). Moreover, participants thought that sexuality was virtually inexistent among the elderly and questioned the need of screening for them: "For old people, I think it's not necessary [...] I don't think 70-year-old people have a sex life" (female patient no. 2).

\section{Criticism of public policies}

Several patients, particularly those older than 40 , considered the cost of public health to be another barrier. "Why incur those costs for the community?" (female patient no. 6). Criticisms concerned public health policies and communication aimed at the general public: anticipated benefits of screening and lack of information about screening methods. Information overload was also criticized as it could lead to information saturation and induce distrust in prevention campaigns: "Too much info kills the info. [...] You get overloaded and you want to think about something else" (female patient no. 13).

\section{HIV beliefs and perceptions}

Fear of HIV-associated illness was considerable for some. Knowledge about this subject, even vague, only exacerbates this apprehension: "some people wouldn't dare to participate, because they're afraid [...]. This disease scares people" (female patient no. 16). The fear of test result can add to that of the disease: "They're afraid to go find out the result" (male patient no. 9).

The lack of screening of 'others' was viewed critically: "I think they don't think they have any chance of catching it, they feel well and have no symptoms, they don't think they're carriers" (female patient 18). However, a concurrent feeling of being personally protected could exist: "Not everyone is in danger of catching that disease [...] From that point of view, I'm completely safe" (male patient no. 4). Living in France could also provide a feeling of protection: "It depends on the country. I don't think France is much affected" (male patient no. 8).

Patients also reported the embarrassment that sometimes prevents them from discussing about HIV, even with their physician: "To be honest I thought of asking him, but I don't really dare ask the doctor" (female patient no. 19). "It's a taboo subject [...] it's like it's something you shouldn't talk about" (male patient no. 23).

\section{Discussion}

Our results provide a better insight into barriers to the HIV mass screening from the patients point of view and clarify their beliefs and perceptions.

The only mode of HIV transmission clearly identified by the interviewed patients was sexual contact. HIV was associated with unprotected sexual intercourses and infidelity, and patients were often unaware of the other modes of transmission, such as contact with blood or blood product (e.g. blood transfusion, intravenous drugs use, tattooing, piercings) and mother-to-child [33,34]. The fact that HIV transmission means sexual intercourse in patients' mind, the HIV mass screening was susceptible to question fidelity within couple, to acknowledge the sexuality of the elderly and to raise discrepancies with religion. These factors could constitute barriers to the implementation of the screening.

The HIV mass screening could be perceived as questioning the fidelity between spouses and thus to be difficult to accept. How could patients agree to be screened for a disease against which the presumed fidelity of their spouse is supposed to protect them? The theme of fidelity (or infidelity) within relationships has been extensively studied in social sciences. According to studies conducted in Europe, Canada and the United States, near one third of men and one fifth of women have had relations outside of the couple [35]. Infidelity is found in all social classes in all countries, including the most repressive [35]. Despite these results, this widespread perception in patients was an obstacle to applying the recent French recommendations concerning HIV screening. 
Patients believed that the screening was useless for patients over the age of 70 , considering their sexuality as virtually non-existent or even disturbing. Although old age is associated with a decrease in desire and impulsivity, and sometimes with pain during the act [36], the sexuality of seniors is much more common than perceived in our sample. Sexual activity persisted into old age, sometimes with multiple partners [37]. In a study conducted in 1998 among a 80-102-year-old group, in residential retirement facilities, some had more than one partner [38]. Moreover, sex tourism of the elderly is also a factor in the transmission of sexual infections, for both men and women [39]. In 2003 and early 2004, the distribution of new cases of HIV and AIDS diagnosed in France, presented a rise over the age of 54, especially among men. From 2003 to 2006, nearly one out of six of all positive screening tests recorded were men over the age of 50 [40]. More recently, it has been estimated that by 2015 , more than half of the patients seropositive for HIV in the United States would be more than 50 [41]; this population should be a new target of HIV screening [42]. Thus, even if age-related physiological changes can alter sexuality, the risk of infection by the AIDS virus remains well and truly real and should not be ignored by patients.

Some participants reported a religiosity that could be another barrier to systematic HIV screening. Catholicism is the most prevalent religion in France [43] and the Catholic Church promotes premarital chastity and is opposed to condom use [44] even if this is a more reliable method. Programs which only promote sexual abstinence are not effective in reducing the risk of HIV transmission [45-47]. Interviewed patients did not dwell on these controversies but mentioned that the Catholic religion could protect them against HIV if its rules were fully respected. This feeling of protection provided by religion could be another obstacle to screening acceptance.

\section{Limitation of the study}

Our study took place in Yvelines, which is one of the most prosperous areas in France thus the patients we interviewed were not representative of the French population. However, the aim of this qualitative study was to get a better insight of the barriers coming from patients themselves towards the untargeted HIV screening, while avoiding potential subjective bias of the researchers. On the basis of our results, further quantitative studies can now be considered to quantify and rank the different factors according to their importance.

\section{Conclusion and recommendations}

Systematic HIV screening in low-risk population is currently recommended by the French Health Authority [21] according to a favorable cost/effective ratio in recent studies [14]. Even if relevance of this screening is still debated $[8,48]$, it seemed important to focus on the patients' view, beyond the medico-economic considerations. Further HIV information campaigns could focus on the less frequent transmission modes in order to improve the general public awareness and change its perception about HIV mass screening. Talking about sexuality should be less taboo in the patient-doctor relationship and religious feeling could be more considered by practitioners when discussing with patients about HIV screening.

HIV mass screening implementation could reduce the number of new cases of HIV contamination and we think our results could facilitate patient-physician discussion regarding this screening.

\section{Box 1: Summary of the barriers to HIV mass screening}

HIV transmission was only associated with sexual relations

HIV screening inevitably questioned spouse's fidelity

Religion (Catholicism) was supposed to protect patients from high-risk relations

Sexuality was supposed virtually inexistent among the elderly

Cost in Public Health

Lack of information about screening methods

Fear of HIV / fear of the result

Feeling of being personally protected, specially by living in France

\section{Appendix 1: Interview grid}

1) The first for a "populational" angle, that of public health. The issue will be presented with the question: "There are new recommendations to screen the whole general population for HIV, from the age of 15 to 70 . Do you think the whole French population should be screened for HIV?". This will generate a consideration of the advantages and disadvantages of a health policy.

2) The second for a more "personal" angle:

"Have you ever been screened for HIV?", to take stock.

- If the answer is "yes":

- was this following a high-risk situation?

- "yes" $\rightarrow$ would you be screened outside of a high-risk situation?

- "no" $\rightarrow$ what were your reasons?

- was it to know your status?

- "yes" $\rightarrow$ what were your reasons?

- "no" $\rightarrow$ under what circumstances?

$\bullet \bullet$ If the answer is "no": 
- would you only get screened in a high-risk situation?

- "yes": for what reasons?

- "no": for what reasons?

- would you get screened outside of a high-risk situation?

- "yes": for what purposes?

- "no": for what purposes?

3) The third, after information on the subject:

- Among the 150,000 people infected with HIV in France, $1 / 3$ or 50,000 are unaware. According to you, what are the reason(s) for this figure?

- On a personal level, knowing these figures, would you get screened outside of a high-risk situation?

- "yes": why?

- "no": why?

\section{Competing interest}

The authors declare that they have no competing interests.

\section{Authors' contributions}

MPF carried out the analysis and interpretation of data, EB participated in the design, revising it critically for important intellectual content, OSL participated in the design of the study, analysis and interpretation of data and final approval of the version to be published. All authors read and approved the final manuscript.

\section{Acknowledgements}

We would like to thank the department of general practice of the University of Versailles Saint-Quentin en Yvelines, and specially the Doctors Le Morzadec, Sebbag, Bersand and Piriou for their precious help. We would also like to thank Evelyne Lefebvre.

\section{Author details}

'Department of Infectious and Tropical Diseases, Bichat-Claude Bernard Hospital, Paris, France. ${ }^{2}$ Department of General Medicine, Faculty of Health Sciences Simone Veil, University of Versailles Saint-Quentin-en-Yvelines, Montigny le Bretonneux, France.

Received: 2 January 2013 Accepted: 24 May 2013

Published: 30 May 2013

\section{References}

1. UNAIDS: Global report 2010. 2010. http://www.unaids.org/en/media/unaids/ contentassets/documents/unaidspublication/2010/20101123_globalreport_ en.pdf.

2. Cazein F: L'infection à VIH-sida en France en 2009: dépistage, nouveaux diagnostics et incidence. Bull Epidemiol Hebd. 2010, 45-46:451-454.

3. Le Vu S, Le Strat Y, Barin F, Pillonel J, Cazein F, Bousquet V: Populationbased HIV-1 incidence in France, 2003-08: a modelling analysis. Lancet Infect Dis 2010, 10(10):682-687.

4. Le Vu SLSY, Barin F, Pillonel J, Cazein F: Incidence de l'infection par le VIH en France, 2003-2008. Bull Epidemiol Hebd. 2010, 45-46:473-476.

5. Cazein F: Surveillance de l'infection à VIH et du SIDA en France. Situation au 31 mars 2004, Surveillance nationale des maladies infectieuses 2001-2003 -2004; Paris. Paris: Institut National de Veille Sanitaire; 2004.

6. Gallien S: Stratégies d'utilisation des antirétroviraux, Stratégies Thérapeutiques en Pathologie Infectieuse P, editor. Paris: University of Paris 7; 2011.

7. Dépistage de l'infection par le VIH en France: Stratégies et dispositif de dépistage. Paris: HAS; 2009. [updated 2009; cited 15 Juillet 2011]; Available from: www.has-sante.fr.

8. D'Almeida KW, Kierzek G, De Truchis P, Le Vu S, Pateron D, Renaud B: Modest public health impact of nontargeted human immunodeficiency virus screening in 29 emergency departments. Arch Intern Med 2012, 172(1):12-20.
9. Vital signs: HIV testing and diagnosis among adults--United States, 2001-2009. Morb Mortal Wkly Rep 2010, 59(47):1550-1555.

10. Aggarwal A, Spitzer RF, Caccia N, Stephens D, Johnstone J, Allen L: Repeat screening for sexually transmitted infection in adolescent obstetric patients. J Obstet Gynaecol Can 2010, 32(10):956-961.

11. Gongidi P, Sierakowski JJ, Bowen GS, Jacobs RJ, Fernandez MI: Survey of Attitudes and Practices of Osteopathic Primary Care Physicians Regarding Taking of Sexual Histories and HIV Screening. J Am Osteopath Assoc 2010, 110(12):712-720.

12. Leonard L, Berndtson K, Matson P, Philbin M, Arrington-Sanders R, Ellen JM: How physicians test: clinical practice guidelines and HIV screening practices with adolescent patients. AIDS Educ Prev 2010, 22(6):538-545.

13. Long EF, Brandeau ML, Galvin CM, Vinichenko T, Tole SP, Schwartz A: Effectiveness and cost-effectiveness of strategies to expand antiretroviral therapy in St. Petersburg, Russia. AIDS 2006, 20(17):2207-2215.

14. Yazdanpanah Y, Sloan CE, Charlois-Ou C, Le Vu S, Semaille C, Costagliola D: Routine HIV screening in France: clinical impact and cost-effectiveness. PLoS One 2010, 5(10):e13132.

15. Cazein F: Dépistage du VIH et découvertes de séropositivités, France 2003-2010. Bull Epidemiol Hebd 2011, 43-44:446-454.

16. Burke RC, Sepkowitz KA, Bernstein KT, Karpati AM, Myers JE, Tsoi BW, et al: Why don't physicians test for HIV? A review of the US literature. AIDS 2007, 21(12):1617-1624.

17. Hutchinson MK, Vandevanter N, Phelan J, Malamud D, Vernillo A, Combellick J, et al: Feasibility of implementing rapid oral fluid HIV testing in an urban University Dental Clinic: a qualitative study. BMC Oral Health 2012, 12(1):11.

18. Guyane ORdlSd: Connaissances et freins en matière de dépistage du VIH/SIDA chez les primo-migrants originaires d'Haiti et du Surinam vivant en Guyane. Guyane: Observatoire Régional de la Santé ; 2003. [updated 2009; cited 15 Juillet 2011]; Available from http://www.infos-guyane.com/depistage-vihsida-migrants-haiti-surinam-guyane/

19. Brown J, Shesser R, Simon G, Bahn M, Czarnogorski M, Kuo I, et al: Routine HIV screening in the emergency department using the new US Centers for Disease Control and Prevention Guidelines: results from a highprevalence area. J Acquir Immune Defic Syndr 2007, 46(4):395-401.

20. Hsu H, Walensky RP: Cost-effectiveness analysis and HIV screening: the emergency medicine perspective. Ann Emerg Med 2011, 58(1 Suppl 1):S145-S150

21. Irvin CB: Public health preventive services, surveillance, and screening: the emergency Department's potential. Acad Emerg Med 2000, 7(12):1421-1423.

22. Laxminarayan R, Mills AJ, Breman JG, Measham AR, Alleyne G, Claeson M: Advancement of global health: key messages from the Disease Control Priorities Project. Lancet 2006, 367(9517):1193-1208.

23. Lyons MS, Lindsell CJ, Ledyard HK, Frame PT, Trott AT: Health department collaboration with emergency departments as a model for public health programs among at-risk populations. Public Health Rep 2005, 120(3):259-265.

24. Paltiel AD, Weinstein MC, Kimmel AD, Seage GR 3rd, Losina E, Zhang $H$ : Expanded screening for HIV in the United States-an analysis of costeffectiveness. N Engl J Med 2005, 352(6):586-595.

25. Sanders GD, Bayoumi AM, Sundaram V, Bilir SP, Neukermans CP, Rydzak CE, et al: Cost-effectiveness of screening for HIV in the era of highly active antiretroviral therapy. N Engl J Med 2005, 352(6):570-585.

26. Myers JJ, Koester KA, Dufour MS: Barriers and facilitators to enhancing HIV testing in publicly funded primary care clinics: findings from San Francisco. AIDS Educ Prev 2011, 23(3 Suppl):84-95.

27. McCoy SI, Miller WC, MacDonald PD, Hurt CB, Leone PA, Eron JJ: Barriers and facilitators to HIV testing and linkage to primary care: narratives of people with advanced HIV in the Southeast. AIDS Care 2009, 21(10):13131320.

28. Prost A, Griffiths CJ, Anderson J, Wight D, Hart GJ: Feasibility and acceptability of offering rapid HIV tests to patients registering with primary care in London (UK): a pilot study. Sex Transm Infect 2009, 85(5):326-329.

29. Blanchet A, Gotman A, Singly FD: L'entretien. Paris: A. Colin; 2007.

30. Quivy R, Van Campenhoudt L: Manuel de Recherche en Sciences Sociales. Paris: Dunod; 1988

31. Green J, Thorogood N: Qualitative methods for health research. London: Sage Publications; 2004

32. Duchene S, Haegel F, Singly FD: L'entretien collectif. Paris: A. Colin; 2008 
33. Brewer DD: Knowledge of blood-borne transmission risk is inversely associated with HIV infection in sub-Saharan Africa. J Infect Dev Ctries 2011, 5(3):182-198.

34. Brewer DD, Potterat JJ, Brody S: Comprehensive assessment of blood and sexual exposures needed for rigorous investigation of HIV transmission. AIDS Res Hum Retroviruses 2012, 28(5):435-436.

35. Dallaire Y: La réalité de l'infidélité. Editions Jouvence: L'infidélité; 2007

36. Avis NE: Sexual function and aging in men and women: community and population-based studies. J Gend Specif Med 2000, 3(2):37-41.

37. Lindau ST, Schumm LP, Laumann EO, Levinson W, O'Muircheartaigh CA Waite $L$ : A study of sexuality and health among older adults in the United States. N Engl J Med 2007, 357(8):762-774.

38. Bretschneider JG, McCoy NL: Sexual interest and behavior in healthy 80- to 102-year-olds. Arch Sex Behav 1988, 17(2):109-129.

39. Michel F: Voyages, Plaisirs et Transgressions; vers un tourisme sexuel de masse? Le Monde Diplomatique 2006, 18:3. Aout 2006.

40. Cazein F: L'infection à VIH/SIDA en France et en Europe. Bull Epidemiol Hebd. 2007, 46-47:386-393.

41. Vance DE, McGuinness T, Musgrove K, Orel NA, Fazeli PL: Successful aging and the epidemiology of HIV. Clin Interv Aging 2011, 6:181-192.

42. Adekeye OA, Heiman HJ, Onyeabor OS, Hyacinth HI: The new invincibles: HIV screening among older adults in the U.S. PLoS One 2012, 7(8):e43618

43. Les Français et la croyance religieuse: Sondage Ifop pour le Journal du Dimanche. Paris: Journal du Dimanche; 2011. [updated 2011; cited June 2011]; Available from: http://www.ifop.com/?option = com_publication \&type $=$ poll\&id $=1479$

44. Galaud F: Pour Benoit XVI le préservatif aggrave le problème du sida. Paris: Le Figaro; 2009. [updated 2009; cited June 2011]; Available from: http://www. lefigaro.fr/international/2009/03/17/01003-20090317ARTFIG00469-pourbenoit-xvi-le-preservatif-aggrave-le-probleme-du-sida-.php.

45. L'Eglise sans complexe à la conférence mondiale sur le SIDA: Dépêche AFP. Paris: Agence France Presse; 2008. 5 Août 2008.

46. Hampton T: Abstinence-only programs under fire. JAMA 2008 , 299(17):2013-2015.

47. Underhill K, Montgomery P, Operario D: Sexual abstinence only programmes to prevent HIV infection in high income countries: systematic review. BMJ 2007, 335(7613):248

48. Cremieux AC, D'Almeida KW, De Truchis P, Simon F, Le Strat Y, Bousquet V, et al: Undiagnosed HIV prevalence based on nontargeted screening in emergency departments. AIDS 2012, 26(11):1445-1448.

doi:10.1186/1471-2458-13-526

Cite this article as: Fernandez-Gerlinger et al:: What do patients think about HIV mass screening in France? A qualitative study. BMC Public Health 2013 13:526.

\section{Submit your next manuscript to BioMed Central and take full advantage of:}

- Convenient online submission

- Thorough peer review

- No space constraints or color figure charges

- Immediate publication on acceptance

- Inclusion in PubMed, CAS, Scopus and Google Scholar

- Research which is freely available for redistribution 